\title{
Comparison of ocean heat content from two eddy-resolving hindcast simulations with OFES1 and OFES2
}

\author{
Fanglou Liao ${ }^{1,2}$, Xiao Hua Wang ${ }^{2,3 *}$ and Zhiqiang Liu ${ }^{1,4 *}$ \\ ${ }^{1}$ Department of Ocean Science and Engineering, Southern University of Science and Technology, Shenzhen, 518055, China \\ $5 \quad{ }^{2}$ The Sino-Australian Research Consortium for Coastal Management, School of Science, The University of New South Wales, \\ Canberra, 2610, Australia \\ ${ }^{3}$ College of Oceanic and Atmospheric Sciences, Ocean University of China, Qingdao, 266100, China \\ ${ }^{4}$ Southern Marine Science and Engineering Guangdong Laboratory (Guangzhou), Guangzhou, 511458, China \\ Correspondence to: Zhiqiang Liu (liuzq@sustech.edu.cn) or Xiao Hua Wang (x.h.wang@unsw.edu.au)
}

10 Abstract. The ocean heat content (OHC) estimates from high-resolution hindcast simulations from the Ocean General Circulation Model for the Earth Simulator Version 1 (OFES1) and Version 2 (OFES2), and a global objective analysis of subsurface temperature observations (EN4.2.1) were compared. There was an OHC increase in most of the global ocean over a 57-year period, mainly a result of vertical displacements of neutral density surfaces. However, we found substantial differences in the temporal and meridional distributions of the OHC between the two OFES hindcasts. The spatial distributions

15 of potential-temperature change also differed significantly, especially in the Atlantic Ocean. The spatial distributions of the time-averaged surface heat flux and heat transport from the OFES1 and OFES2 were highly correlated, but differences could be seen. However, these differences, more specifically in the heat transport, were only partially responsible for the OHC differences. The marked OHC differences may arise from the different vertical mixing schemes and may impact the largescale pressure field, and thus the geostrophic current. The work here should be a useful reference for future OFES users.

\section{Introduction}

The global ocean has stored over $90 \%$ of the extra heat added to the Earth system since 1955, causing a significant increase in $\mathrm{OHC}$ (Levitus et al., 2012). The change in the $\mathrm{OHC}$ is therefore an important indicator of climate change and provides useful bounds in estimating the Earth's energy imbalance (Palmer et al., 2011; Von Schuckmann et al., 2016). Although natural factors such as the El Niño-Southern Oscillation (ENSO) and volcanic eruptions can affect the OHC (Balmaseda et al., 2013; Church et al., 2005), the recent warming has mostly resulted from greenhouse gases accumulating in the atmosphere (Abraham et al., 2013; Gleckler et al., 2012; Pierce et al., 2006).

Several approaches exist to fill the temporal and spatial gaps in global temperature measurements, and can be used to produce gridded temperature fields to estimate the $\mathrm{OHC}$. These approaches include the objective analysis of observational data, ocean reanalysis by physical ocean models constrained by observations. In addition, ocean general-circulation models (OGCMs) also provide the temperature field by solving the primitive equations of fluid motions and states. Although OGCMs are dynamically consistent, some are not constrained by observations. How multi-scale dynamical processes are represented in these unconstrained models and their implementation of external forcing will significantly impact their OHC estimates.

The Ocean General Circulation Model for the Earth Simulator (OFES; Masumoto et al., 2004; Sasaki et al., 2004), developed by the Japan Agency for Marine-Earth Science and Technology (JAMSTEC) and other institutes, is a well-known eddy-resolving ocean model, and the hindcast simulation of the OFES Version 1 (OFES1) has been widely used (Chen et al., 2013; Dong et al., 2011; Du et al., 2005; Wang et al., 2013). The hindcast simulation based on the OFES Version 2 (OFES2) is now publicly available, and certain improvements have been made over the OFES1 (Sasaki et al., 2020). To our knowledge, however, comparisons of the multi-decadal OHC from the OFES1 and OFES2 are lacking. As this high-resolution quasi-global model is expected to be widely used in the oceanography and climate communities for examining the ocean state in the near 
future, there is a need to compare the OHC estimates from these two OFES versions as an indicator of the potential improvements in the OFES2 over the OFES1.

The aim of this paper is twofold: (1) to estimate the OHC in the global ocean and each major basin using the OFES1 and OFES2 with primary focus on their differences; (2) to understand the causes of differences between these two simulations. To this end, we used the potential temperature $\theta$ to calculate the OHC from 1960 to 2016 for both the global ocean and the major basins, the Pacific Ocean, the Atlantic Ocean and the Indian Ocean, between $64^{\circ} \mathrm{S}$ and $64^{\circ} \mathrm{N}$.

In addition, we decomposed the changes in the potential temperature $\Delta \theta$ into heaving (HV) and spiciness (SP) components following Bindoff and McDougall (1994). The time-averaged surface heat flux and heat transport from the OFES1 and OFES2 were compared to understand the $\mathrm{OHC}$ budget. We used the results from an observation-based objective analysis product EN4.2.1 (EN4) as a reference.

50 In the following section, we give a brief description to the data and methods used in this paper (section 2 ). In section 3 , we describe and discuss the differences between the datasets in both temporal and spatial domains; a tentative analysis of the possible causes responsible for the examined discrepancies is conducted. Sections 4 summaries the principal points and makes an extension about other factors that are not examined here due to data availability but could be important, and therefore some future work is expected for improvements on our work here.

\section{Data and Methods}

\subsection{Data}

Potential-temperature data from both the OFES1 and OFES2 were used to calculate the global and basin OHC for comparison with each other and with the OHC calculated from the observation-based potential temperature of the EN4. Although results from the EN4 cannot be taken as the actual oceanic state, it has been widely used in OHC-related studies (Allison et al., 2019;

60 Carton et al., 2019; Häkkinen et al., 2016; Trenberth et al., 2016; Wang et al., 2018). A brief description of the three datasets is given below; readers are referred to Sasaki et al. (2004), Sasaki et al. (2020) and Good et al. (2013) for more details.

We considered only water from the sea surface to around $1400 \mathrm{~m}$. This can be justified by the definition of major water masses in Emery (2001): the upper ocean is from the surface to a depth of $500 \mathrm{~m}$ and the intermediate ocean from $500 \mathrm{~m}$ to $1500 \mathrm{~m}$. We set the upper ocean to be from the surface to around $500 \mathrm{~m}$, and the intermediate ocean between around $500 \mathrm{~m}$ and $1400 \mathrm{~m}$ to minimize the differences in vertical-layer thickness among the datasets. The ocean beneath is ignored because the deep ocean highly depends on the spin-up of the numerical running, which is almost surely incomplete (Wunsch 2011), at least in the first decade.

The OFES1 has a horizontal spatial resolution of $0.1^{\circ}$ and 54 vertical levels from $5 \mathrm{~m}$ to a maximum depth of $6065 \mathrm{~m}$ (Sasaki et al., 2004); this high spatial resolution enables it to include mesoscale processes. The multi-decadal integration period makes it possible to perform an analysis of oceanic fields at decadal-to-multidecadal scales. Following a 50-year climatological simulation, the hindcast simulation of the OFES1 is integrated from 1950 to two years ago. Unlike most other data used for OHC estimates, the OFES1 is an ocean modelling with no observation data involved. Therefore, it can be used to demonstrate the potential benefits of high resolution and the adaptability of pure numerical modelling.

The OFES2 also has a horizontal spatial resolution of $0.1^{\circ}$. Vertically, there are 105 layers, with a maximum depth of 7500 m. The OFES1 uses daily National Centers for Environmental Prediction (NCEP) reanalysis $\left(2.5^{\circ} \times 2.5^{\circ}\right.$; Kalnay et al., 1996) for the surface momentum and heat fluxes, whereas the OFES2 is forced by the 3-hourly atmospheric surface dataset JRA55do Version $08(55 \mathrm{~km} \times 55 \mathrm{~km}$; Tsujino et al., 2018). Therefore, both the temporal and spatial resolutions of the surface forcing have increased significantly in the OFES2. It also incorporates river runoff and sea-ice models.

In the horizontal direction, both the OFES1 and OFES2 use a biharmonic mixing scheme. The horizontal diffusivity 80 coefficient varies proportional to the cube of the cosine of the latitude and equals $-9 \times 10^{9} \mathrm{~m}^{4} / \mathrm{s}$ at the Equator (Smith et al., 2000). The OFES2 uses a mixed-layer vertical mixing scheme (Noh and Jin Kim 1999) with parametrization of tidal-energy 
dissipation (Jayne and St. Laurent 2001; St. Laurent et al., 2002), whereas the OFES1 uses the K-profile parameterization scheme (Large et al., 1994). With the oceanic field on $1^{\text {st }}$ Jan 1958 from the OFES1 as the initial conditions, the OFES2 used here has been integrated from 1958 to 2016. To limit the computation cost, we subsampled the OFES1 and OFES2 simulations every 5 grid points in the horizontal direction.

To validate the OHC from the two sets of OFES data, we used the EN4 from the UK Met Office Hadley Centre as a reference. The monthly EN4 data can be considered as an objective analysis that is primarily based on observations (Good et al., 2013), with a horizontal resolution of $1^{\circ}$ and 42 vertical levels from $5 \mathrm{~m}$ to $5350 \mathrm{~m}$. The EN4 assimilates data mainly from the World Ocean Database (WOD) and the Coriolis dataset for ReAnalysis (CORA). Pre-processing and quality checks are conducted before the observational data are used to construct this objective analysis product.

Although we use the EN4 results as a reference for evaluating the OFES performance in simulating the 57-year ocean thermal state, it is also worthy to note that the EN4 cannot be taken as the actual ocean state. The main reason is that the measurements used to construct the EN4 datasets are sparse and inhomogeneous in both the temporal and spatial domains, and far from sufficient to resolve mesoscale or even sub-mesoscale motions. There were more observations in the northern

95 hemisphere than in the southern hemisphere, and a higher density of records became available only after the World Ocean Circulation Experiment (WOCE) in the 1990s and installation of the Argo profiling floats in the 2000s. Table 1 summarizes these three ocean datasets.

Table 1. Description of the OFES1, OFES2 and EN4 datasets.

\begin{tabular}{cccc}
\hline & OFES1 & OFES2 & EN4 \\
\hline Model & MOM3 & MOM3 & - \\
Horizontal coverage & $75^{\circ} \mathrm{S}-75^{\circ} \mathrm{N}$ & $76^{\circ} \mathrm{S}-76^{\circ} \mathrm{N}$ & $83^{\circ} \mathrm{S}-89^{\circ} \mathrm{N}$ \\
Grids & $3600 \times 1500$ & $3600 \times 1520$ & $360 \times 173$ \\
Maximum depth & $6065 \mathrm{~m}$ & $7500 \mathrm{~m}$ & $5350 \mathrm{~m}$ \\
Vertical levels & 54 & 105 & 42 \\
Atmospheric forcing & Daily NCEP/NCAR reanalysis & 3-hourly JRA55-do ver.08 & - \\
Data assimilated & - & - & WOD, CORA \\
Time span & since 1950 & since 1958 & since 1900 \\
\hline \hline
\end{tabular}

\subsection{Methods}

100 We compared the three datasets during the period between 1960-2016. Although the two OFES datasets may not be well spun up in the beginning, especially the OFES2, we focus on their differences on a multi-decadal scale. Following convention, the $\mathrm{OHC}$ values here are the $\mathrm{OHC}$ anomalies relative to 1960 . At each grid point, the $\mathrm{OHC}$ was calculated as $\mathrm{OHC}=\rho \delta v C_{p}\left(\theta-\theta_{1960}\right)=\rho \delta v C_{p} \Delta \theta$,

where $\rho$ is the seawater density, $\delta v$ the grid volume, $C_{p}$ the specific heat of seawater at constant pressure, $\theta$ the potential temperature and $\theta_{1960}$ the potential temperature in 1960. A value of $4.1 \times 10^{6} \mathrm{~kg} \mathrm{~J} \mathrm{~m}^{-3} \mathrm{~K}^{-1}$ was used for the product of $\rho$ and specific heat of seawater $C_{p}$ (Palmer et al., 2011).

Both the global and individual-basin OHCs were calculated for comparison. Figure 1 shows the domains of the Pacific, Atlantic and Indian Oceans between $64^{\circ} \mathrm{S}$ and $64^{\circ} \mathrm{N}$, with their respective marginal seas included. 


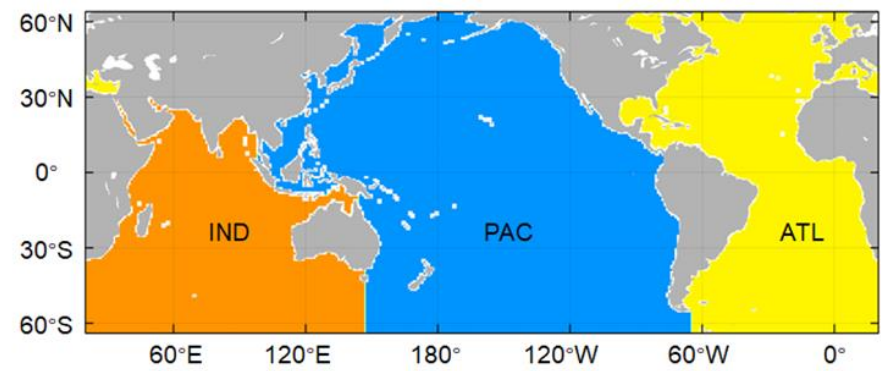

110 Figure 1. Major basins, the Pacific Ocean (PAC), the Atlantic Ocean (ATL) and Indian Ocean (IND), between $64^{\circ} \mathrm{S}$ and $64^{\circ} \mathrm{N}$. Grey indicates land.

The changes in the potential temperature $\Delta \theta$ were decomposed into an SP component (second term in Eq. (2) below) and an HV component (third term in Eq. (2)) (Bindoff and McDougall 1994). HV is the Eulerian measure of $\Delta \theta$ at fixed depths, resulting from the vertical displacement of neutral surfaces (Häkkinen et al., 2016). SP represents changes along the neutral

115 surfaces. This decomposition helps to identify the dominant mechanisms changing the potential temperature. The formula decomposing the potential temperature is

$d \theta / d t \mid z=\overbrace{d \theta / d t \mid n}^{\mathrm{SP}}-\overbrace{d z / d t \mid n d \theta / d z}^{\mathrm{HV}}$

We used the program by Jackett and McDougall (1997) to calculate the neutral densities, HV and SP. The main inputs for this program are the potential temperature $\theta$ and salinity $S$. As the code limits the latitude domain to between $80^{\circ} \mathrm{S}$ and $64^{\circ} \mathrm{N}$, we set our investigation domain to between $64^{\circ} \mathrm{S}$ and $64^{\circ} \mathrm{N}$ to avoid comparisons in sea-ice impacted areas (only OFES2 includes a sea-ice model).

\section{Results}

The principal aim here is to compare the results from the OFES1and OFES2, with the EN4 acting as an observation-based reference. If there is a significant difference between the OFES2 result and that of one or both of the other two datasets, does this represent a real phenomenon not present in the other two widely used datasets or is it an unwanted property of the newly released OFES2 simulation? In this section, we compare the three sets of results for the global ocean, and for each of the Pacific, Atlantic and Indian Oceans individually. The first task is to identify significant differences.

\subsection{Time evolution of the OHC, HV and SP from 1960 to 2016}

In this section, we compare the $\mathrm{OHC}$ time series from the three datasets and with some important findings in the literature.

\section{$a$ The upper ocean $(\mathbf{0 - 5 0 0} \mathrm{m})$}

In Fig. 2a, the EN4 shows that the global upper ocean experienced cooling during the 1960s, followed by an approximately linear warming ("linear warming" used here is as a short-hand for "warming at a linear rate") since the 1970s (Achutarao et al., 2007; Zanna et al., 2019). Although this cooling is reproduced in both the OFES datasets, the linear warming appeared in 1994 and 1999 in the OFES1 and OFES2, respectively, more than 20 years later than that in the EN4. In addition, the warming rate in the global upper-layer ocean after 1994 was around $4.3 \mathrm{ZJ} / \mathrm{yr}$ from the EN4 and 4.9 ZJ/yr from the OFES1 $\left(1 \mathrm{ZJ}=10^{21} \mathrm{~J}\right.$ and yr means year), but only $1.0 \mathrm{ZJ} / \mathrm{yr}$ from the OFES2. Unlike in the other datasets, a sharp and remarkable OHC reduction stood out in the OFES1 in 1987 (Fig. 2a).

In the upper layer of the Pacific Ocean (Fig. 2b), The result from the EN4 shows that the upper layer of the Pacific Ocean was largely warming with some sporadic exceptions. Conversely, the OFES products indicate an overall cooling but in different ways. More specifically, the OFES1 indicates cooling before 1987 in the upper Pacific Ocean, with a sudden cooling 
then occurring. The cooling trend then reversed to warming. In the upper layer of the Atlantic Ocean (Fig. 2c), the OHC time series from the EN4 and the OFES1 are highly correlated (Fig. 2c), with a correlation coefficient of 0.9. In addition, the overall warming rate was around $1.0 \mathrm{ZJ} / \mathrm{yr}$ from the EN4 and $0.8 \mathrm{ZJ} / \mathrm{yr}$ from the OFES1. Strikingly, the OFES2 presents a notable cooling of $1.4 \mathrm{ZJ} / \mathrm{yr}$ before 2000 . Overall, the absolute differences between the three products in the upper layer of the Indian Ocean are the smallest (Fig. 2d), with the OFES2 showing larger OHC increase before 2010. A summary of the total warming rate in the upper ocean from 1960-2016 is given in Tab. 2. When compared to the EN4, the OFES data show much weaker warming or even cooling, especially the OFES2.

The calculated HV and SP can help identify how the ocean water warms or cools (Häkkinen et al., 2016). The HV dominated the OHC variations (Figs. 2e-h) and evolved substantially different to the SP (Figs. 2i-1). This means that the OHC variations largely result from the vertical movement of the neutral surfaces over this 57-year period, as seen in all three products. The HV dominance in OHC variations was also examined in Häkkinen et al. (2016). One interesting point is that the EN4 and OFES1 agrees quite well in the SP of the upper layer of the Pacific Ocean, although their HV results there are significantly different. In the upper layers of the Atlantic and Indian Oceans, SP variations are almost negligible.

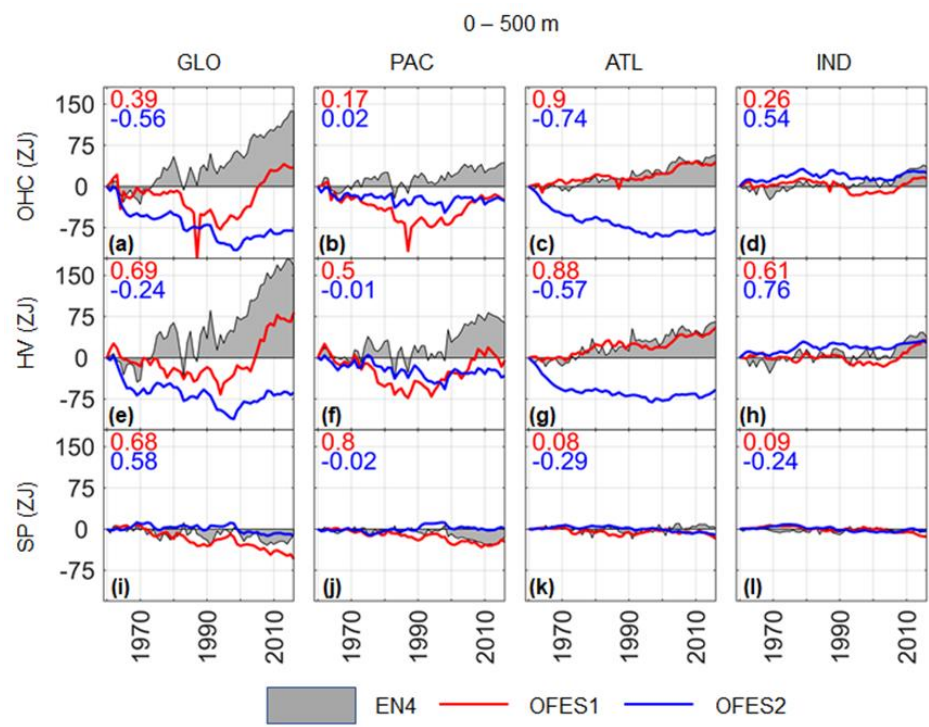

155 Figure 2. Time evolution of the global and basin-wide OHC (top), HV (middle) and SP (bottom) in the upper ocean (0$500 \mathrm{~m}$ ) based on the three temperature products. Grey shadow: EN4; red solid line: OFES1; blue solid line: OFES2. Numbers in the top left corners are the correlation coefficients between the OFES1 (red) or OFES2 (blue) and EN4.

Table 2. The trend (italic) and standard deviations (number in the bracket) of the OHC temporal evolutions in Fig. 2.

The unit for the trend is $\mathrm{ZJ} / \mathrm{yr}$ and for the standard deviation is ZJ. The trend is calculated by dividing the OHC in 2016 by 56.

\begin{tabular}{cccc}
\hline \hline & EN4 & OFES1 & OFES2 \\
\cline { 2 - 4 } GLO & $2.4(45.2)$ & $0.62(34.6)$ & $-1.4(27.5)$ \\
PAC & $0.77(16.1)$ & $-0.44(24.6)$ & $-0.47(8.9)$ \\
ATL & $1.0(19.7)$ & $0.80(14.1)$ & $-1.4(23.0)$ \\
IND & $0.65(13.8)$ & $0.26(9.6)$ & $0.45(7.2)$ \\
\hline
\end{tabular}




\section{$b$ The intermediate ocean $(500-1400 \mathrm{~m})$}

In the intermediate layer of the global ocean (500-1400 m, Fig. 3a), the EN4 and OFES1 are alike in indicating a relatively stable state for the global intermediate ocean before 1990, but an approximately linear warming trend afterwards, at a warming rate of $2.8 \mathrm{ZJ} / \mathrm{yr}$ from the EN4 and $2.5 \mathrm{ZJ} / \mathrm{yr}$ from the OFES1. This agrees well with the trend based on NOAA/NODC (Cheng et al. 2016). The OFES2 indicates a cooling of $1.3 \mathrm{ZJ} / \mathrm{yr}$ before 1998 , then warming at a rate of $1 \mathrm{ZJ} / \mathrm{yr}$.

In the intermediate layer of the Pacific Ocean (Fig. 3b), the EN4 OHC were closer to the OFES2, both of which shows slight or even negligible OHC variations. On the contrary, The OFES1 indicates a distinct warming rate of $1.2 \mathrm{ZJ} / \mathrm{yr}$. In the intermediate layer of the Atlantic Ocean (Fig. 3c), the OHC profile from the OFES1 is similar to that of the EN4, with both of them indicating a relatively stable $\mathrm{OHC}$ before the $2000 \mathrm{~s}$, and a subsequent approximately linear warming. Although the results from the OFES2 show that the intermediate layer of the Atlantic Ocean was cooling before the middle of the 1990s, the two OFES products are similar from around 2000, with a warming of $1.0 \mathrm{ZJ} / \mathrm{yr}$ from the OFES1 and $0.6 \mathrm{ZJ} / \mathrm{yr}$ from the OFES2. The warming rate over the same period was larger in the $\mathrm{EN} 4$, reaching $1.4 \mathrm{ZJ} / \mathrm{yr}$. The $\mathrm{OHC}$ variation in the intermediate layer of the Indian Ocean is rather weak except from the EN4 (Fig. 3d), which displays a moderate warming from around the middle of the 1990s. Despite the similarity in the OHC in the global intermediate ocean between the EN4 and OFES1 (Fig. 3a), the differences in the basin $\mathrm{OHC}$ estimates were notable. Interestingly, these basin differences together contribute to the similarity in the global OHC in the intermediate ocean between the EN4 and OFES1. Tab. 3 summaries the total warming rate in the intermediate ocean over 1960-2016. On the one hand, although the OFES1 shows the global ocean and basins warms, as shown in the EN4, the intensity is quite different for each basin. On the other hand, a general weak or moderate cooling was presented by the OFES 2 .

Similar to the upper ocean, the HV accounts for much more of the OHC variation than the SP in the intermediate ocean. Indeed, only the OFES2 shows moderate SP components in each of the three major basins (especially in the intermediate layer of the Indian Ocean), and thus significant SP variations in the global intermediate ocean. Despite the magnitude differences, both the EN4 and OFES1 show increases in the HV in the intermediate layers of the Pacific and Atlantic Oceans, whereas the HV estimates from the OFES2 largely decreased with time.

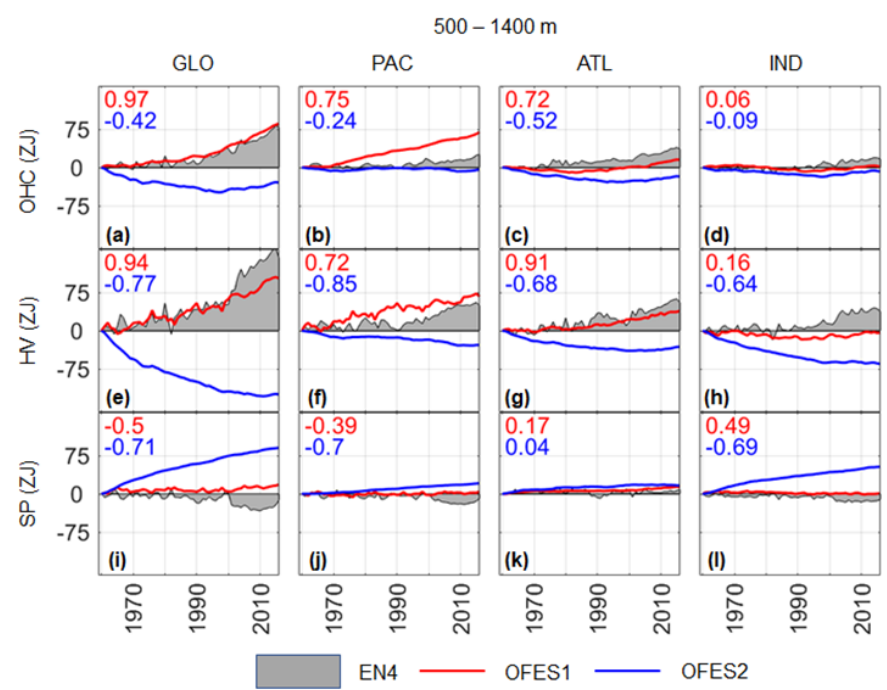

Figure 3. As for Fig. 2 but for the intermediate ocean (500-1400 m). 
Table 3. As for Tab.2 but for the intermediate ocean between 500-1400 m.

\begin{tabular}{lccc}
\hline \hline & EN4 & OFES1 & OFES2 \\
\cline { 2 - 4 } GLO & $1.4(23.9)$ & $1.5(25.3)$ & $-0.53(11.6)$ \\
PAC & $0.46(6.7)$ & $1.2(21.1)$ & $-0.07(2.2)$ \\
ATL & $0.65(11.5)$ & $0.27(6.7)$ & $-0.32(7.8)$ \\
IND & $0.30(7.6)$ & $0.02(3.8)$ & $-0.14(4.4)$ \\
\hline \hline
\end{tabular}

\subsection{Meridional distribution of the zonal-integrated OHC, HV and SP}

The previous section presented the time evolution of the global and basin OHC quantitatively. To show the simulated and observed meridional variations in the OHC, we calculated the zonal-integrated OHC increase (2014-2016 average minus 1960-1962 average; ZJ per degree of latitude) for both the global ocean and the major basins (Figs. 4, 5). As the horizontal resolutions of the EN4 and the OFES hindcasts are different, we calculated the $\mathrm{OHC}$ increase in each latitude band of $1^{\circ}$ from $64^{\circ} \mathrm{S}$ to $64^{\circ} \mathrm{N}$, rather than on the native grid of these data. For clarity of presentation, we denoted these two periods as P1 (1960-1962) and P2 (2014-2016).

\section{$a$ The upper ocean $(0-500 \mathrm{~m})$}

In the upper layer of the global ocean (Fig. 4a), both the EN4 and OFES1 show an almost consistent warming in the upper extratropical region, except for the region $60^{\circ}$ poleward (Fig. 4a). Moreover, these two datasets capture a common warming peak of approximately $7 \mathrm{ZJ}$ at around $40^{\circ} \mathrm{S}$. The major differences between the OFES1 and the EN4 are seen in the upper tropical ocean, a region with consistent warming in the EN4 but two troughs at around $15^{\circ} \mathrm{S}$ and $15^{\circ} \mathrm{N}$ in the OFES1. The two OFES datasets give similar trends in the southern tropical region, with a trough of $\mathrm{OHC}$ indicated by both.

In each of the major basins, the EN4 shows moderate OHC increases in the upper layer for almost the whole examined latitude range, with a few sporadic exceptions. In the upper layer of the Pacific Ocean (Fig. 4b), the two OFES datasets are more similar to each other in the Southern Hemisphere than in the Northern Hemisphere. Similar to the EN4, the OFES1 also indicates that warming existed over almost the whole latitude range of the upper layer of the Atlantic Ocean (Fig. 4c). In contrast, the OFES2 suggests marked $\mathrm{OHC}$ decreases between $50^{\circ} \mathrm{S}$ and $30^{\circ} \mathrm{N}$ of the upper Atlantic Ocean. In the upper layer

210 of the Indian Ocean (Fig. 4d), all three datasets present quite small OHC variations in the Northern Hemisphere. However, south of the Equator, the OFES1 is highly close to the EN4, both of which presenting a notable warming peak at around $45^{\circ} \mathrm{S}$. A distinct warming peak also appears in the OFES2, but about $15^{\circ}$ equatorward. The HV clearly contributes the bulk of the $\mathrm{OHC}$ variations for almost the whole latitude range (Figs. 4e-h); the SP variations only becomes comparable to the HV at some latitudes (Figs. 4i-1). 


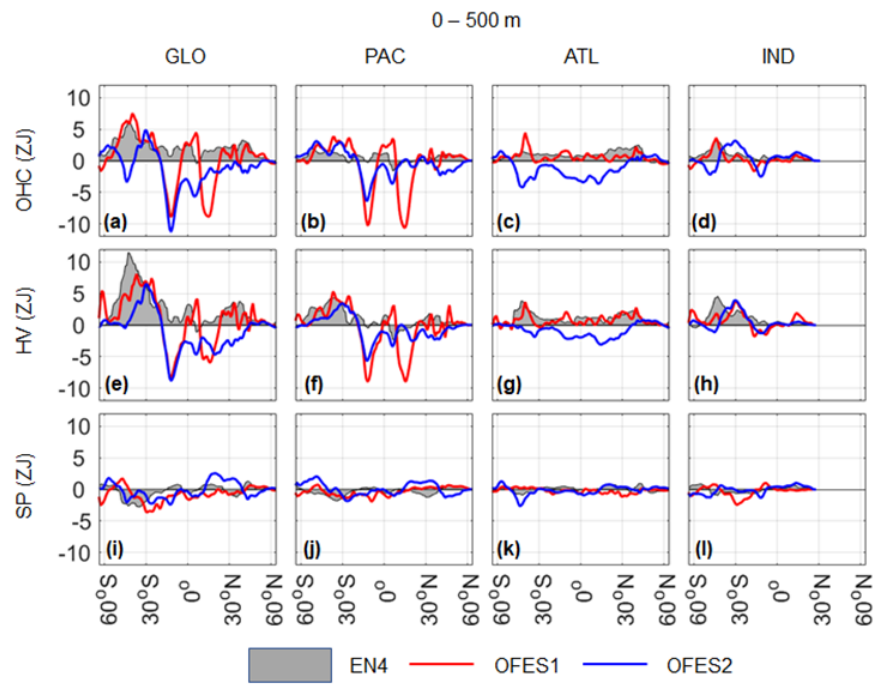

Figure 4. Zonal-integrated OHC (top), HV (middle) and SP (bottom) increase (2014-2016 average minus 1960-1962 average, $\mathrm{ZJ}$ per degree of latitude) versus latitude in the upper ocean $(0-500 \mathrm{~m})$. Domain: $64^{\circ} \mathrm{S}$ to $64^{\circ} \mathrm{N}$. Grey shadow: EN4; red solid line: OFES1; blue solid line: OFES2.

\section{$b$ The intermediate ocean $(500-1400 \mathrm{~m})$}

In the global intermediate ocean (Fig. 5a), the meridional OHC distributions show again the closeness between the EN4 and OFES1, both having a marked warming peak between around $40-45^{\circ} \mathrm{S}$. Their major disagreements are seen in the northern tropic. Between $40^{\circ} \mathrm{S}$ and $30^{\circ} \mathrm{N}$, there are negative $\mathrm{OHC}$ variations in the OFES2, which also missed the large warming peak (between around $40-45^{\circ} \mathrm{S}$ ) above-mentioned by the other two.

As for the meridional OHC distribution in the intermediate layer of the Pacific Ocean (Fig. 5b), the OFES2 agrees well with the EN4 between around $64^{\circ} \mathrm{S}$ and $25^{\circ} \mathrm{S}$. To the north of $60^{\circ} \mathrm{S}$ in the intermediate layer of the Pacific Ocean, the OFES1 indicates a consistent $\mathrm{OHC}$ increase, whereas the $\mathrm{OHC}$ is shown to slightly decrease between $30^{\circ} \mathrm{S}$ and $20^{\circ} \mathrm{N}$ in the OFES2. As indicated by the EN4, warming is present at almost all the latitudes considered in the intermediate layer of the Atlantic Ocean (Fig. 5c). However, cooling can be seen in the OFES data in different latitudal intervals. The OFES1 resembles the EN4 in the southern Indian Ocean (Fig. 5d) in presenting a significant warming peak slightly to the north of $50^{\circ} \mathrm{S}$, but this peak is missed by the OFES2. In spite of this distinction, the OFES2 also reveals a large OHC increase near the Equator, just as the other two.

The HV component again dominates the OHC variations over almost the whole latitude range. Both the EN4 and OFES2 suggest moderate SP variations, especially the latter. In the EN4, moderate SP variations are located at around $40^{\circ} \mathrm{S}$ in the Pacific and Indian Oceans, but not in the intermediate Atlantic Ocean. 


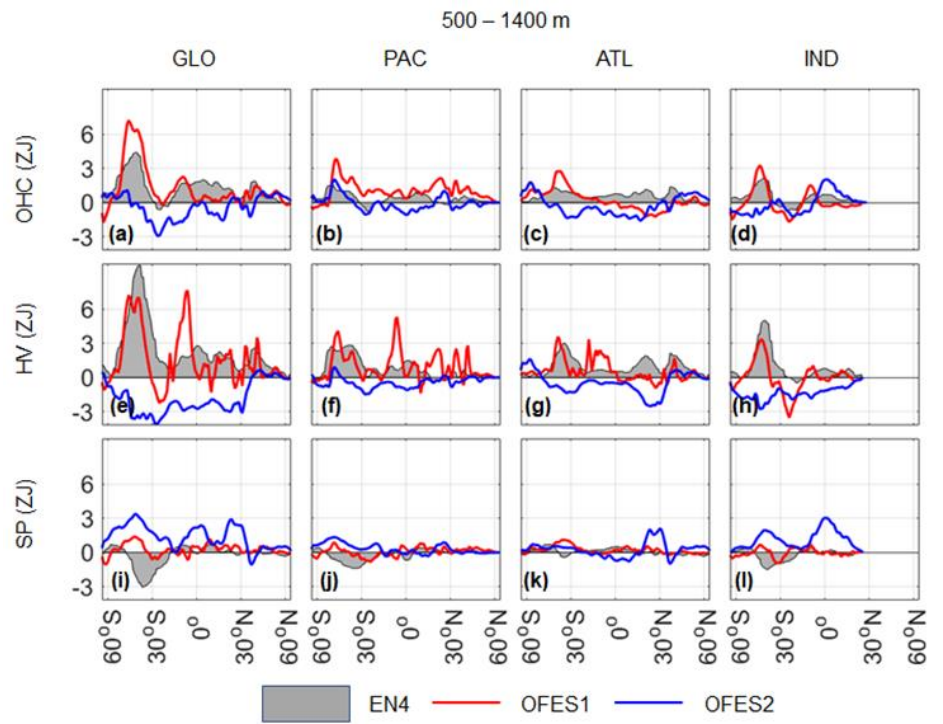

Figure 5. As for Fig. 4 but in the intermediate ocean (500-1400 m).

\subsection{Spatial patterns of the potential-temperature changes}

The two previous sections described the global and basin-wide OHC distributions in the temporal domain and the longitudinal direction quantitatively. To further investigate the detailed agreements and discrepancies in the warming or cooling from these three datasets, we calculated the volume-averaged potential temperature $\theta_{\mathrm{OHC}}$. This was calculated by dividing the total $\mathrm{OHC}$ variations in the water column of each ocean layer (upper or intermediate) by the corresponding total water volume and the product of seawater density and specific heat capacity $\left(\rho \times C_{p}=4.1 \times 106 \mathrm{~kg} \mathrm{Jm}^{-3} \mathrm{~K}^{-1}\right)$. We then compared the change in the volume-averaged potential temperature, $\Delta \theta_{\mathrm{OHC}}(\mathrm{P} 2$ average (2014-2016) minus P1 average (1960-1962)) from the different datasets, as shown in Fig. 6. We also calculated $\Delta \theta_{\mathrm{HV}}$ and $\Delta \theta_{\mathrm{SP}}$, derived from the $\mathrm{HV}$ and SP, respectively, in a similar way. The reason for using $\Delta \theta$ rather than the $\mathrm{OHC}$ is that the latter is an extensive quantity, but its variation at each grid is directly related to the $\Delta \theta$. To facilitate interpreting the results, we defined major water masses for both the upper and intermediate oceans in each basin, following Emery (2001), as shown in Tabs. 4 and 5. Readers are referred to Emery (2001) for more details. The geographical distribution of the major water masses analysed here can be found in Emery (2001). 
https://doi.org/10.5194/gmd-2021-95

Preprint. Discussion started: 20 April 2021

(c) Author(s) 2021. CC BY 4.0 License.

Table 4. Characteristics of the major water masses in the upper ocean $(0-500 \mathrm{~m})$. The temperature value $\left({ }^{\circ} \mathrm{C}\right)$ is connected by "." and the salinity value (\%o) connected by “ ".

\begin{tabular}{|c|c|c|c|}
\hline & Pacific Ocean & Atlantic Ocean & Indian Ocean \\
\hline \multirow{8}{*}{$\begin{array}{c}\text { Water } \\
\text { mass } \\
(0-500 \\
\text { m) }\end{array}$} & $\begin{array}{l}\text { 1. Pacific Subarctic Upper Water } \\
\text { (PSUW), 3-15, 32.6 33.6. }\end{array}$ & $\begin{array}{l}\text { 1. Atlantic Subarctic Upper Water } \\
\text { (ASUW), } 0-4,34 \sim 35 \text {. }\end{array}$ & $\begin{array}{l}\text { 1. Bengal Bay Water (BBW), } \\
25-29,28 \sim 35 \text {. }\end{array}$ \\
\hline & $\begin{array}{l}\text { 2. Western North Pacific Central Water } \\
\text { (WNPCW),10-22, 34.2 35.2. }\end{array}$ & $\begin{array}{l}\text { 2. Western North Atlantic Central } \\
\text { Water (WNACW), 7-20, 35 36.7. }\end{array}$ & $\begin{array}{l}\text { 2. Arabian Sea Water (ASW), } \\
24-30,35.5 \sim 36.8 \text {. }\end{array}$ \\
\hline & $\begin{array}{l}\text { 3. Eastern North Pacific Central Water } \\
\text { (ENPCW), 12-20, 34.2 35. }\end{array}$ & $\begin{array}{l}\text { 3. Eastern North Atlantic Central } \\
\text { Water (ENACW), 8-18, 35.2 36.7. }\end{array}$ & $\begin{array}{l}\text { 3. Indian Equatorial Water } \\
\text { (IEW), } 8-23,34.6 \sim 35.0 \text {. }\end{array}$ \\
\hline & $\begin{array}{l}\text { 4. Eastern North Pacific Transition } \\
\text { Water (ENPTW), 11-20, 33.8 34.3. }\end{array}$ & $\begin{array}{l}\text { 4. South Atlantic Central Water } \\
\text { (SACW), 5-18, 34.3 35.8. }\end{array}$ & $\begin{array}{l}\text { 4. Indonesian Upper Water } \\
\text { (IUW), 8-23, 34.4 35.0. }\end{array}$ \\
\hline & $\begin{array}{l}\text { 5. Pacific Equatorial Water (PEW),7- } \\
23,34.5 \sim 36 \text {. }\end{array}$ & & $\begin{array}{l}\text { 5. South Indian Central Water } \\
(\mathrm{SICW}), 8-25,34.6 \sim 35.8 \text {. }\end{array}$ \\
\hline & $\begin{array}{l}\text { 6. Western South Pacific Central Water } \\
\text { (WSPCW),6-22, 34.5 35.8. }\end{array}$ & & \\
\hline & $\begin{array}{l}\text { 7. Eastern South Pacific Central Water } \\
\text { (ESPCW), 8-24, 34.4 36.4. }\end{array}$ & & \\
\hline & $\begin{array}{l}\text { 8. Eastern South Pacific Transition } \\
\text { Water (ESPTW), 14-20, 34.6 35.2. }\end{array}$ & & \\
\hline
\end{tabular}

Table 5. Same with Tab. 4, but for the intermediate ocean (500-1400 m).

\begin{tabular}{|c|c|c|c|}
\hline & Pacific Ocean & Atlantic Ocean & Indian Ocean \\
\hline $\begin{array}{c}\text { Water } \\
\text { mass } \\
(500- \\
1400 \mathrm{~m})\end{array}$ & $\begin{array}{l}\text { 1. Pacific Subarctic } \\
\text { Intermediate Water (PSIW), 5-12, } \\
33.8 \sim 34.3 \text {. } \\
\text { 2. California Intermediate Water } \\
\text { (CIW), 10-12, 33.9 34.4. } \\
\text { 3. Eastern South Pacific } \\
\text { Intermediate Water (ESPIW), 10- } \\
\text { 12, 34.0 34.4. } \\
\text { 4. Antarctic Intermediate Water } \\
\text { (AAIW), 2-10, 33.8 34.5. }\end{array}$ & $\begin{array}{l}\text { 1. Western Atlantic Subarctic } \\
\text { Intermediate Water (WASIW), 3-9, } \\
34.0 \sim 35.1 . \\
\text { 2. Eastern Atlantic Subarctic } \\
\text { Intermediate Water (EASIW), 3-9, } \\
\text { 34.4 35.3. } \\
\text { 3. Antarctic Intermediate Water } \\
\text { (AAIW), 2-6, 33.8 34.8. } \\
\text { 4. Mediterranean Water (MW), 2.6- } \\
\text { 11.0, 35.0 36.2. } \\
\text { 5. Arctic Intermediate Water (AIW), } \\
\text {-1.5-3.0, 34.7 34.9. }\end{array}$ & $\begin{array}{l}\text { 1. Antarctic Intermediate Water } \\
\text { (AAIW), 2-10, 33.8 34.8. } \\
\text { 2. Indonesian Intermediate Water } \\
\text { (IIW), 3.5-5.5, 34.6 34.7. } \\
\text { 3. Red Sea-Persian Gulf } \\
\text { Intermediate Water (RSPGIW), 5- } \\
\text { 14, 34.8 35.4. }\end{array}$ \\
\hline
\end{tabular}




\section{$a$ The upper ocean $(0-500 \mathrm{~m})$}

Both the EN4 and OFES1 suggest that the Pacific Subarctic Upper Water (PSUW, see Tab. 4 for definition) largely warmed (Fig. 6 a, b), whereas the bulk of the PSUW cooled in the OFES2 (Fig. 6c). The OFES1 indicated the strongest cooling pattern in the southern flank of the West North Pacific Central Water (WNPCW) and East North Pacific Central Water (ENPCW), extending eastward to around $120^{\circ} \mathrm{W}$ (Fig. 6b), whereas the other two presented only moderate cooling in the center and on the southern side of WNPCW.

The eastern part of the Pacific Equatorial Water (PEW) is shown to be a warming pool by the OFES1 (Fig. 6b), but the intensity in the EN4 and OFES2 are significantly weaker (Figs. 6a,c). In the West South Pacific Central Water (WSPCW), a cooling tendency is presented in a small region to the southeast of Indonesia in the EN4 (Fig. 6a). This cooling pattern was shown to be much more extensive in both the OFES1 and OFES2, extending to the East South Pacific Central Water (ESPCW) (Figs. 6b,c). Between $180^{\circ} \mathrm{E}$ and $120^{\circ} \mathrm{W}$ in the southern Pacific Ocean, there exists a region with intense cooling shown in the OFES1 (Fig. 6b), but not captured by both the EN4 and OFES2.

In the upper layer of the Atlantic Ocean, the EN4 and OFES1 indicate that there is a cooling tendency associated with the Atlantic Subarctic Upper Water (ASUW) (Fig. 6a, b). In the OFES2, however, there is an intense warming tongue extending from around $30^{\circ} \mathrm{N}$ to the subarctic (Fig. 6c); a part of the ASUW is shown to have a cooling tendency. The Western North Atlantic Central Water (WNACW) was warming in the EN4 and the OFES1, but this did not occur in the OFES2. The differences in the Eastern North Atlantic Central Water (ENACW) are remarkable, with the EN4 indicating moderate warming, the OFES1 minor variations and the OFES2 strong cooling (Figs. 6a-c). Both the EN4 and OFES1 show moderate warming in the Atlantic Equatorial Water (AEW), the OFES2 significant cooling. Warming occurred in the bulk of the South Atlantic Central Water (SACW) in both the EN4 and OFES1 (Fig. 6a, b), whereas the OFES2 suggests cooling, except to the east of South America (Fig. 6c). Furthermore, the OFES2 presents a much stronger warming pattern in the ACC section of the Atlantic Ocean compared to the other two data.

Warming is found in the Arabian Sea Water (ASW), especially in the OFES2 (Fig. 6c), in which the intense warming mainly results from SP, same with the EN4 but opposite to the OFES1. $\Delta \theta$ in the Bengal Bay Water (BBW) is relatively small, except in the OFES1 (Fig. 6b). The weak warming pattern in the Indian Equatorial Water (IEW) in the EN4 is not shown in the other datasets. Large discrepancies occurred in the Indian Ocean section of the ACC, with significant warming in the EN4 and OFES1, but cooling in the OFES2.

In summary, the major patterns are similar in the EN4 and OFES1, but differs in strength and span. Secondly, the discrepancies between the two OFES datasets are marked and comparable to their respective $\Delta \theta$ magnitude, despite some similarities between the OFES1 and OFES2. 

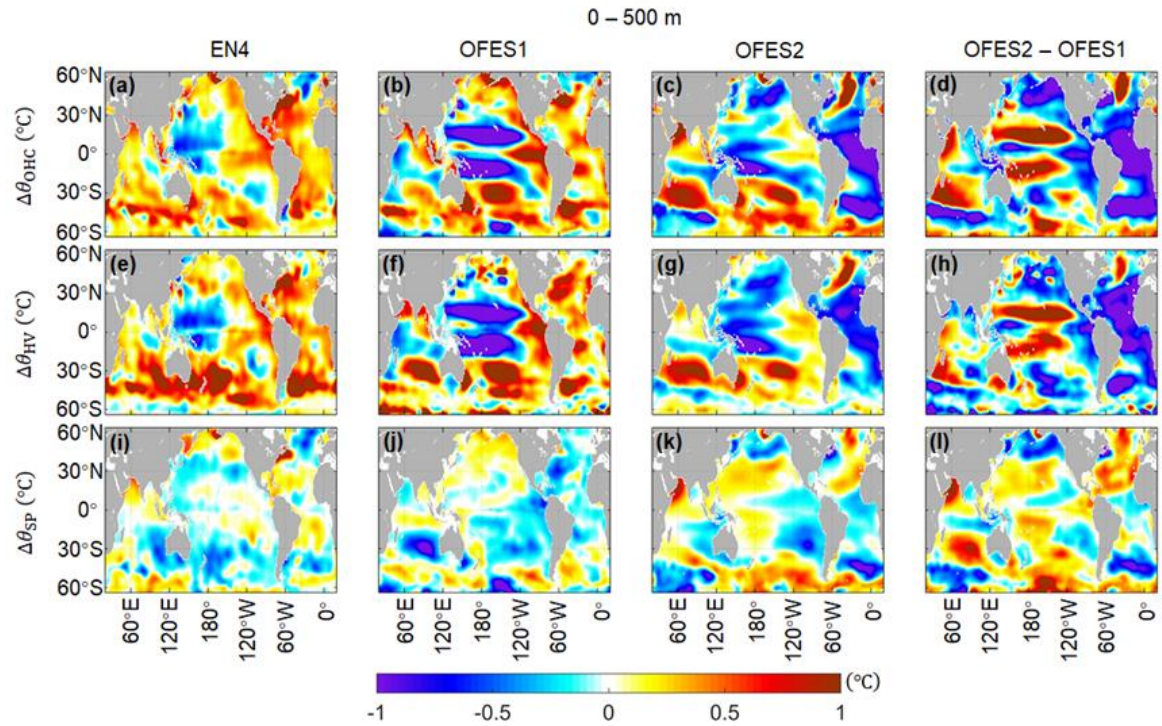

Figure 6. Spatial patterns of $\Delta \theta_{\mathrm{OHC}}$ (top row), $\Delta \theta_{\mathrm{HV}}$ (middle row) and $\Delta \theta_{\mathrm{sP}}$ (bottom row) in the upper ocean $(0-500 \mathrm{~m})$. Potential-temperature change is 2014-2016 average minus 1960-1962 average. First column: EN4; second column: OFES1; third column: OFES2; fourth column: difference between the OFES1 and OFES2.

\section{$b$ The intermediate ocean $(500-1400 \mathrm{~m})$}

In the intermediate layer of the Pacific Ocean, a clear difference between the OFES1 and others is that the former presented most of the Pacific Subarctic Intermediate Water (PSIW) was warming (Fig. 7b). Both the EN4 and OFES1 indicate a slight warming in the California Intermediate Water (CIW), but cooling is shown for the CIW in the OFES2. All three datasets consistently suggest warming in the southern flank of the Antarctic Intermediate Water (AAIW) in the Pacific Ocean (Figs. $7 \mathrm{a}-\mathrm{c}$ ), with the warming shown by the OFES1 strongest. Substantial discrepancies exist in the central and northern parts of the AAIW. More specifically, there is a vast region of cooling in the central part of the AAIW in the southern Pacific Ocean from both the EN4 and OFES2 (Fig. 7a,c), whereas the OFES1 reveals a largely warming pattern. The OFES2 also showed negative $\Delta \theta$ in the region west of the northwestern African continent (Fig. 7c), which cannot be seen in the other two data.

The EN4 indicates that almost the whole intermediate layer of the Atlantic Ocean was warming (Fig. 7a) but there exist regions of intense cooling in the OFES data. For instance, both the OFES1 and OFES2 display cooling in the bulk of the Western Atlantic Subarctic Intermediate Water (WASIW), especially the OFES2 (Fig. 7c). There is a similar warming tongue between $30-60^{\circ} \mathrm{N}$ in the middle of the Atlantic Ocean in the OFES1 and OFES2, but that in the latter much stronger (Figs. $7 \mathrm{~b}, \mathrm{c})$. Both the OFES1 and OFES2 show that the southern flank of the Atlantic branch of the AAIW was warming, but the warming in the OFES1 extended over a longer distance northward to around $30^{\circ} \mathrm{S}$ (Fig. $7 \mathrm{~b}$ ). On the contrary, the EN4 trend on the southern side of the AAIW is much weaker compared to others.

In the Indian Ocean, large discrepancies appear in the Red Sea-Persian Gulf Intermediate Water (RSPGIW): the EN4 shows weak warming (Fig. 7a), whereas the OFES1 and OFES2 indicate intense cooling (moderate warming) and intense warming (moderate cooling) for the eastern (western) parts of the RSPGIW, respectively (Figs. 7b,c). Large differences also happen to in the Indonesian Intermediate Water (IIW). Weak and strong warming is shown by the EN4 and OFES1 (Figs. 7a,b), respectively, but significant cooling in the OFES2 (Fig. 7c). The EN4 and OFES1 display strong warming in the ACC path, whereas intense cooling is indicated by the OFES2. At around $60^{\circ} \mathrm{S}$ in the Indian Ocean, both the OFES datasets show strong cooling (Figs. $7 \mathrm{~b}, \mathrm{c}$ ), but $\Delta \theta$ is quite small in the EN4. 

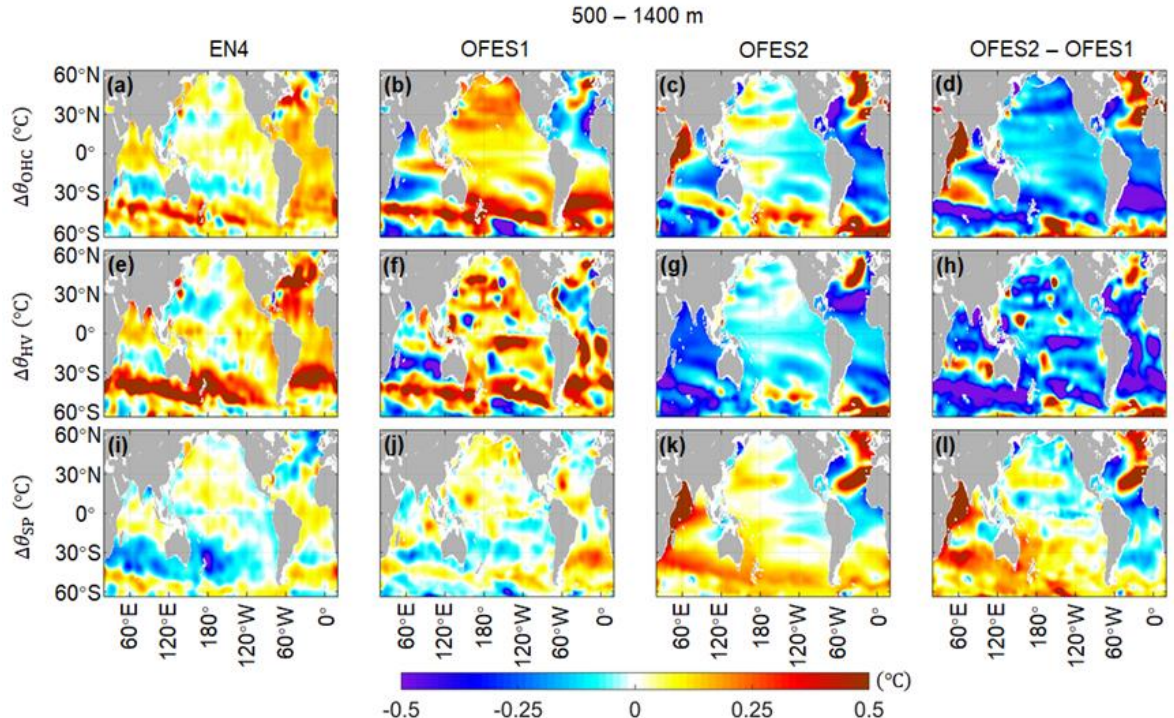

Figure 7. As for Fig.6 but in the intermediate ocean (500-1400 m).

\subsection{Temperature-salinity diagrams}

Figures 6 and 7 in Section 3.3 demonstrated the similarities and differences in the patterns of $\Delta \theta$ by analysing the warming/cooling tendencies in the major water masses (a body of water with specific temperature-salinity characteristics; Tables 2, 3). To further understand the contributions of the different water masses to the OHC variations quantitatively, we constructed a variant of the canonical temperature-salinity $(T-S)$ diagram. In this special $T$-S diagram, we display the total OHC variations in the different temperature and salinity intervals (Figs. 8,9). Note that for a better visualization, we only present the dominant temperature and salinity domains, and have bounded the major water masses by different line styles and colours. As the differences in temperature and/or salinity in different water masses can be quite minor, there are many overlaps in the T-S diagrams. Therefore, Figs. 8 and 9 need to be combined with Figs. 6 and 7 for a clearer interpretation.

\section{$a$ The upper ocean $(0-500 \mathrm{~m})$}

The temperature-salinity characteristics are generally similar in the three datasets, especially the EN4 and OFES2. The T-S diagrams from the EN4 and OFES1 for the Pacific Ocean are similar (Figs. 8e,f); the major discrepancy is associated with the WNPCW, with the EN4 indicating a much smaller OHC decrease, similar to the OFES2 (Fig. 8g). In addition, the PEW is associated with an $\mathrm{OHC}$ increase in all the data. In the Atlantic Ocean, the ASUW contributes to the OHC increase in all the tasets, especially the EN4 and OFES2 (Figs. 8i,k). However, the spatial distribution of $\Delta \theta$ in Fig. $6 \mathrm{c}$ indicates that the ASUW in the EN4 and OFES1 cooled. Therefore, the cooling associated with the ASUW may be compensated by warming of water with similar temperature-salinity characteristics elsewhere. In the WNACW, both the EN4 and OFES1 suggest a notable OHC increase (Figs. 8i,j), whereas there is a large OHC decrease in the OFES2 (Fig. 8k). The ENACW accounts for large and moderate OHC increase in the EN4 and OFES1, respectively, but marked OHC decrease in the OFES2 (Fig. 8k). The IEW leads to large OHC decrease in the OFES1 and OFES2 (Figs. 8n,o), but not in the EN4 (Fig. 8m). The three datasets all indicate significant cooling in the SICW. It is found that a large fraction of $\mathrm{OHC}$ increase by water cooler than $8^{\circ} \mathrm{C}$ in the upper layer of Indian Ocean but not resides in any water masses defined in Tab. 4. Moreover, strong OHC variations (mostly positive) are also associated with the water warmer than the major water masses, especially in the upper layers of the Pacific and Atlantic Oceans, which are related to the near-surface warming. 


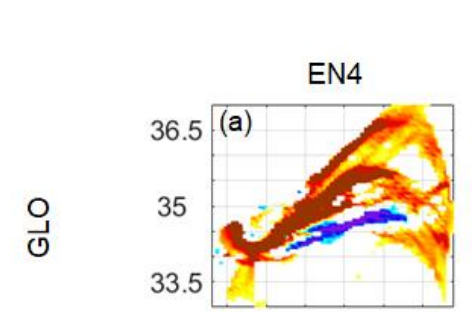

$0-500 \mathrm{~m}$

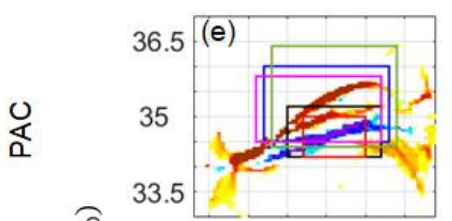

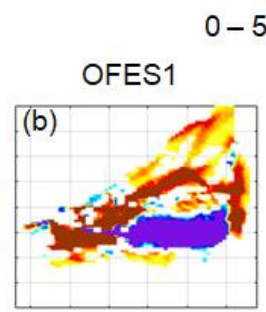

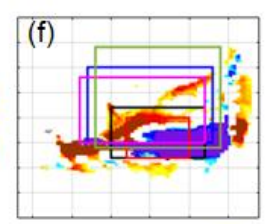

OFES2
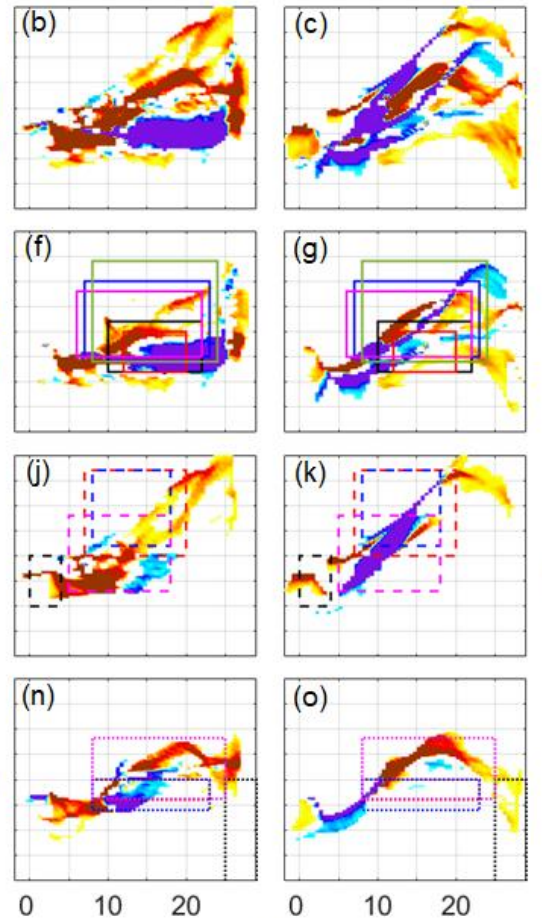

OFES2-OFES1
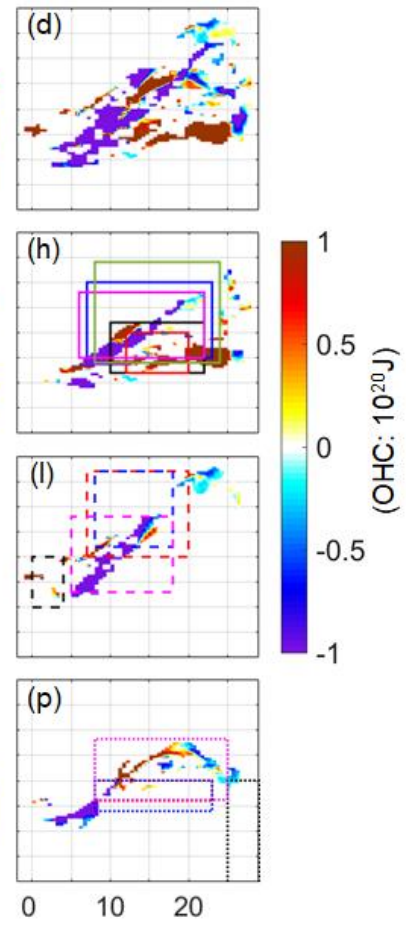

$\theta\left({ }^{\circ} \mathrm{C}\right)$

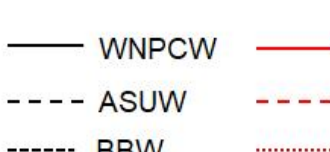

ENPCW - PEW

WSPCW

ESPCW

350

Figure 8. Special T-S diagram showing the contributions to the $\mathrm{OHC}$ from the dominant water masses in the upper ocean $(0-500 \mathrm{~m})$.

\section{$b$ The intermediate ocean $(500-1400 \mathrm{~m})$}

From the T-S diagram (Fig. 9), it can be seen that there are significant differences in salinity in the OFES1 compared to the

EN4 and OFES2, the latter two being similar (for example, Figs. 9a,c). Most of the waters have a warming trend in the EN4 and OFES1 (Figs. 9a,b). However, a remarkable OHC decrease can be seen in the OFES2 (Fig. 9c). More specifically for the OFES2, the AAIW is responsible for the bulk of the OHC increase in the Pacific Ocean (Fig. 9g). In the Atlantic Ocean, the OFES2 shows that almost all the OHC increase came from the EASIW and MW (Fig. 9k). The major OHC increase in the Indian Ocean can be attributed to the RSPGIW in the OFES2 (Fig. 9o). The AAIW of the Indian Ocean is found to account for large OHC increase in the EN4 and OFES1 (Fig. 9 m,n), but just opposite in the OFES2 (Fig. 9o). 

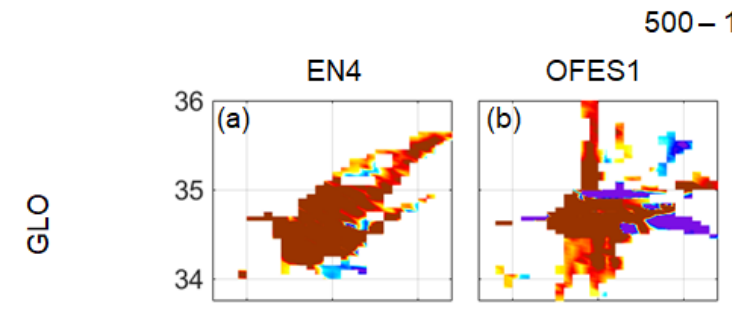

$1400 m$
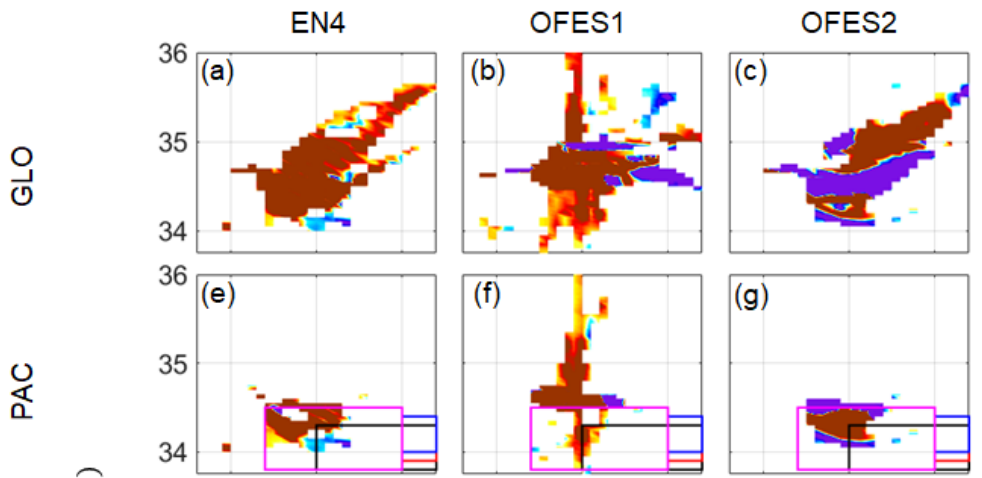

OFES2-OFES1
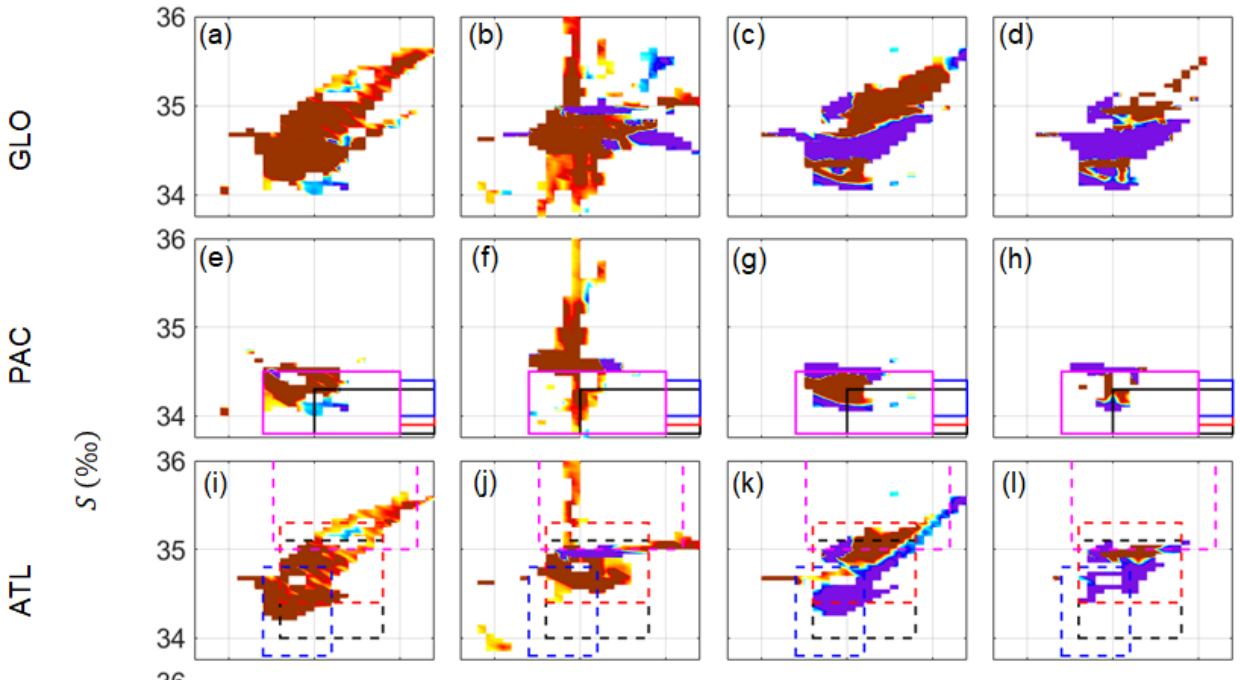

0.5

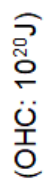
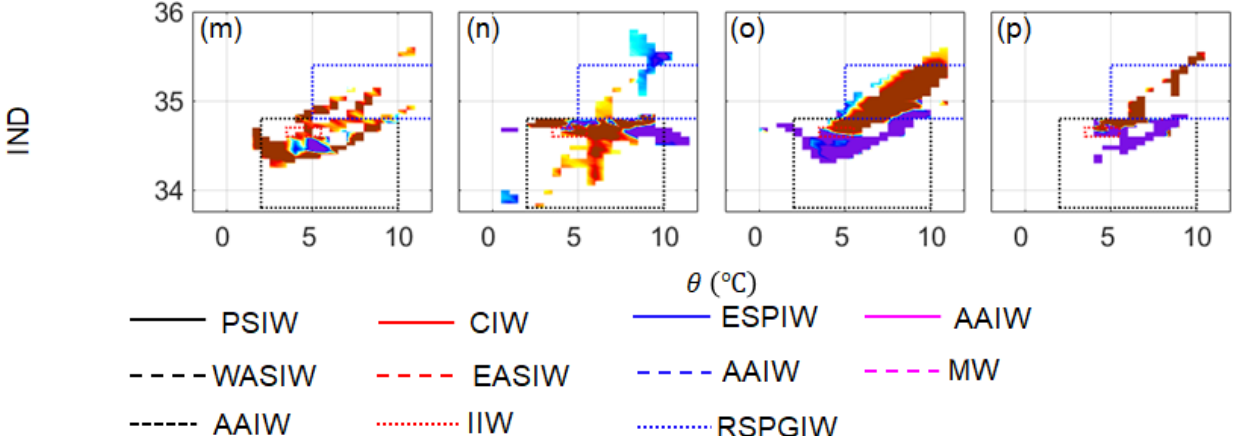

$\theta\left({ }^{\circ} \mathrm{C}\right)$

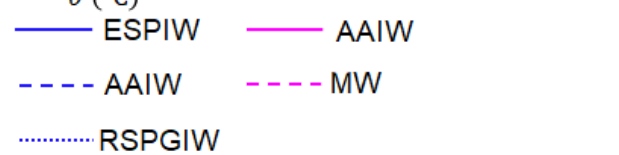

IIW

RSPGIW

Figure 9. As for Fig. 8 but in the intermediate ocean (500-1400 m).

\subsection{Analysis of surface heat flux and heat transport}

The above analyses showed the differences in the estimated $\mathrm{OHC}$ and its related potential temperature change from the OFES1 and OFES2 by comparing them with the observation-based EN4; this section analyses possible causes for the differences. We firstly compare the time-averaged heat flux through the ocean surface from the OFES1 and OFES2 (the source term in the governing equation of temperature; not applicable to the EN4). We also calculate and compare the horizontal and vertical heat transports (the advection terms in the governing equation of temperature), whose differences mainly result from the simulated circulations and temperature fields.

The surface heat-flux patterns from the OFES1 and OFES2 are spatially similar (Figs. 10a, b), but certain differences can be seen in Figs. 10 c,d. Most of the Pacific and Indian Oceans gained less heat or lost more heat in the OFES2, a major exception being the eastern Pacific Equator. Comparing the heat flux distributions in Fig. 10 with the $\Delta \theta$ distributions from the OFES1 and OFES2 in Fig. 6, there is no clearly positive correlation between the surface heat flux and the $\Delta \theta$. For instance, the more intense heat flux in the OFES2 does not lead to a stronger OHC increase in the eastern Pacific Equator. This implies that the examined $\mathrm{OHC}$ or potential temperature differences are caused by other factors. 

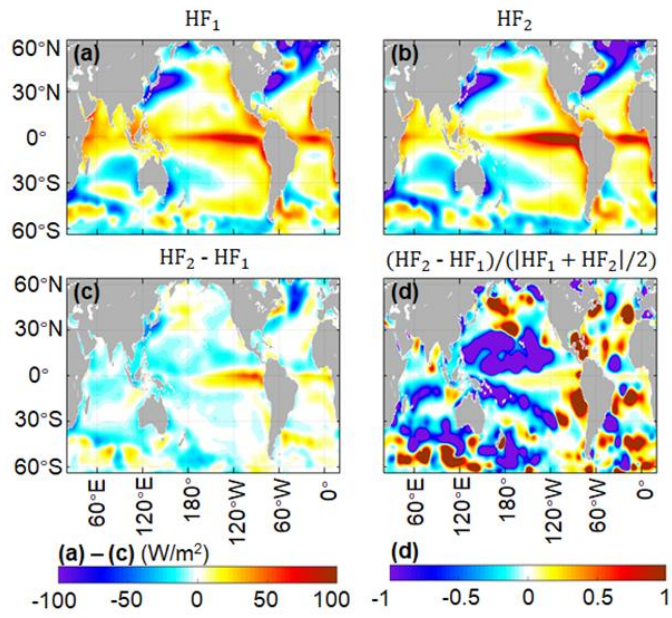

Figure 10. Time-averaged net surface heat flux (HF) from the OFES1 and OFES2. (a) spatial pattern of the HF1 for the OFES1; (b) spatial pattern of the HF2 for the OFES2; (c) absolute differences in the HF between the two sets of OFES data; (d) ratio of the difference to the sum of the HF.

The governing equation of the temperature in an OGCM states that temperature tendency arises from heat sources, the advection and diffusion in both the horizontal and vertical directions. To investigate how the heat transport affect the $\mathrm{OHC}$ or $\Delta \theta$ difference pattern, we calculated the heat transport in the zonal, meridional and vertical directions in the upper ocean (Fig. 11, not applicable to the EN4) and in the intermediate ocean (Fig. 12). In Fig. 11, the zonal (ZHT, per unit width) and meridional (MHT, per unit width) heat transports are vertically integrated between $0 \mathrm{~m}$ and $500 \mathrm{~m}$, and the vertical heat transport (VHT, per unit area) is through the depth of $500 \mathrm{~m}$. Similarly, in Fig. 12, the ZHT and MHT are vertically integrated between the $500 \mathrm{~m}$ and $1400 \mathrm{~m}$, and the VHT as through the depth of $1400 \mathrm{~m}$.

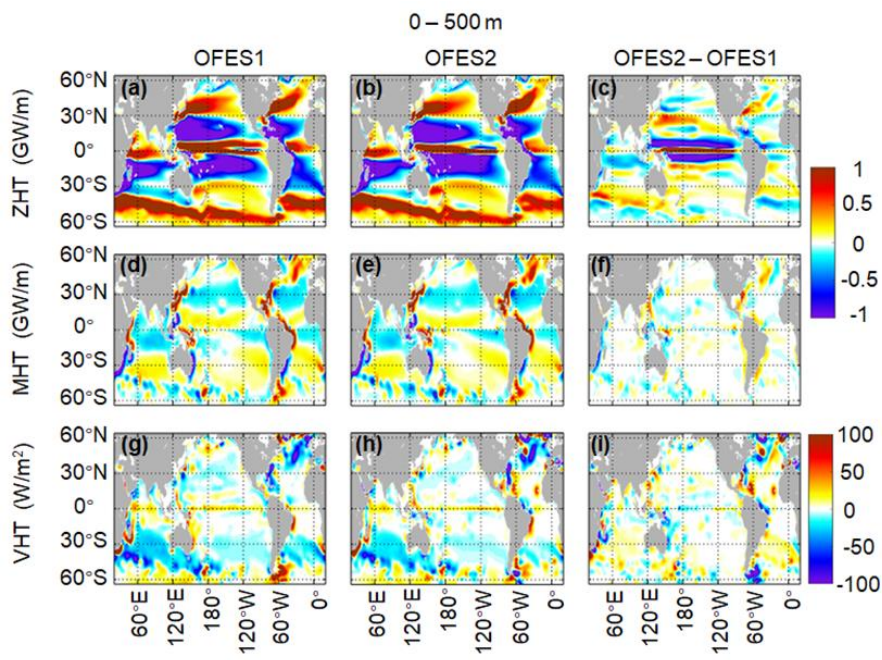

Figure 11. Spatial patterns of the time-averaged zonal (ZHT, top), meridional (MHT, middle) and vertical (VHT, bottom) heat transport from the OFES1 (left) and OFES2 (center), and their differences (right) in the upper ocean (0$500 \mathrm{~m}$ ). ZHT and MHT are vertically integrated between $0 \mathrm{~m}$ and $500 \mathrm{~m}$ per unit width; VHT is the vertical heat flux through the depth of $\mathbf{5 0 0} \mathbf{~ m}$ per unit area. Positive ZHT means heat transport eastward; positive MHT means heat transport northward; positive VHT means heat transport upward. 
The large-scale distribution of the horizontal heat transport is a direct reflection of the general circulation and the upper circulation is mainly wind driven. For simplicity, we will not describe the general patterns of heat transport, which is highly and OFES2 aiming at explaining the $\mathrm{OHC}$ and $\Delta \theta$ disagreements shown above. Specifically, the stronger westward heat transport in the vicinity of the Pacific Equator (Fig. 11c) may be responsible for the weaker cooling associated with the southern flank of the WNPCW and weaker warming of the eastern Pacific Equator (Fig. 6c). The larger eastward heat transport associated with the Kuroshio can also partially explain the weaker warming of the WNPCW within the Kuroshio pathway in the OFES2, at least locally. The stronger ZHT and MHT associated with the Gulf Stream (Figs. 11c, f) in the OFES2 lead to more heat being transported out, and thus to the local weak cooling in Fig. 6c, compared to moderate warming in the OFES1 (Fig. 6b). The notable warming tongue in the middle of the upper Atlantic Ocean at around $35-64^{\circ} \mathrm{N}$ may result from the stronger MHT in the OFES2 (Fig. 11f). However, the extensive cooling trend in the vast area of the upper Atlantic Ocean cannot be well explained by the heat advection here and heat flux in Fig. 10, and thus may be attributed to heat diffusion, which cannot be examined here. In the upper layer of the Indian Ocean, the larger amount of heat transported westward in the southern tropics may be responsible for the stronger cooling trend in the IUW and the much weaker cooling in the western flank of the IEW in the OFES2. In addition, the ZHT associated with the northern part of the ACC in the Indian Ocean is stronger in the OFES2, which may account for the cooling there. The much stronger warming of the central south Indian Ocean may be a result of the lesser downward heat transport there in the OFES2 (Fig. 11i).

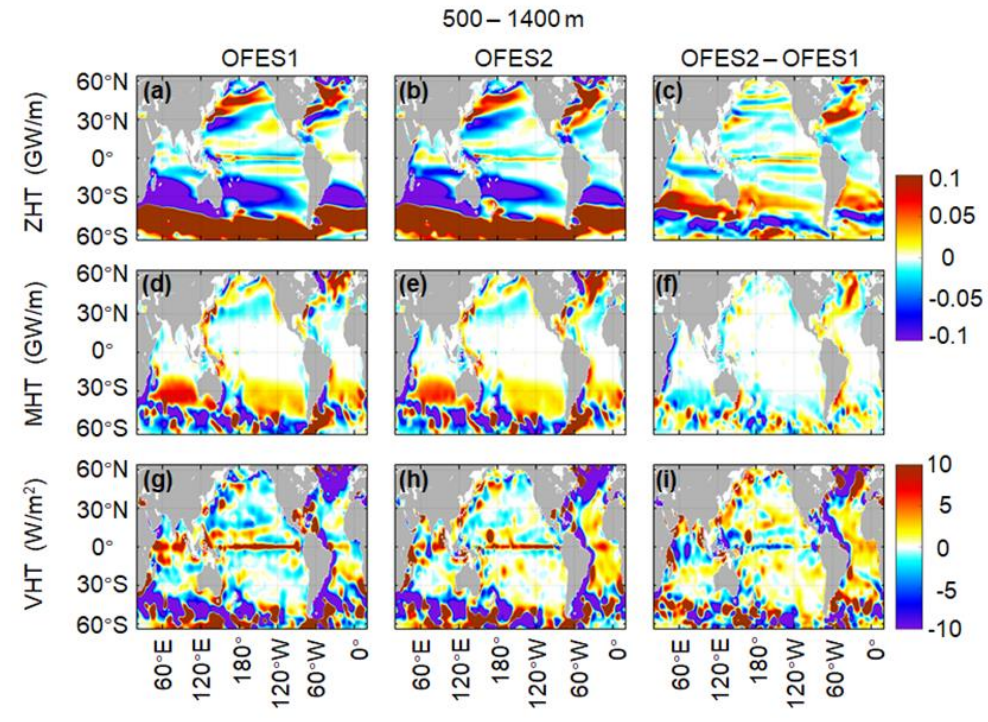

Figure 12. As for Fig. 11 but in the intermediate ocean (500-1400 m). ZHT and MHT are vertically integrated between $500 \mathrm{~m}$ and $1400 \mathrm{~m}$; VHT is the vertical heat flux through the depth of $1400 \mathrm{~m}$.

As shown in Fig. 7, the OFES2, unlike the OFES1, shows cooling in the low and middle latitudes of the intermediate layer of the Southern Atlantic Ocean, which cannot be well explained by the heat transport distribution in Fig. 12. But it may be related to the lesser downward heat transport at the depth of $500 \mathrm{~m}$ (Figs. 11g-i), as less heat was vertically added into the intermediate ocean via its upper boundary. In the intermediate layer of the Atlantic Ocean, the stronger ZHT associated with the Gulf Stream can account for the local larger negative $\Delta \theta$ in the OFES2. In addition, the more intense MHT north of $30^{\circ} \mathrm{N}$ in the Atlantic Ocean contributes to the warming tongue there in the OFES2. The notable warming in the RSPGIW in the OFES2 largely results from greater upward heat transport at the depth of $1400 \mathrm{~m}$. Lesser MHT in the central south Indian Ocean may be related to the strong cooling central and eastern parts of the intermediate layer of the Indian Ocean. In the 
vertical direction, the OFES2 shows upward heat transport consistently between around $30^{\circ} \mathrm{S}-30^{\circ} \mathrm{N}$ in the Atlantic Ocean, but this cannot explain the cooling of the intermediate layer of the Atlantic Ocean in the same horizontal coverage.

\section{Conclusions and Discussion}

In this paper, we estimated the OHC from two high-resolution hindcast simulations OFES1 and OFES2 with major focus on their differences. The global observation-based dataset EN4 acts as a reference and the following principal points were found.

1. Warming was clearly seen in most of the global ocean (0-1400 m), especially by the EN4 and OFES1. The warming was mainly manifested by the vertical displacements of neutral density surfaces (HV), with only minor contributions from changes along the neutral surfaces (SP).

2. Significant differences in the OHC (or potential temperature) were found between the OFES1 and OFES2. The similarly distributed surface heat fluxes could not account for the differences in the warming/cooling distributions. Differences in the horizontal and vertical heat transports were found to be only partially responsible for the revealed OHC differences between the two OFES datasets.

Although we have detailed the OHC differences between the OFES1 and OFES2, and also analysed the horizontal and vertical heat transports in an attempt to understand the causes behind the differences, more work is needed to further understand the causes. Of the various possible causes, we speculate that and being not fully spun up of the OFES2 and vertical mixing could be vital to the subsurface $\mathrm{OHC}$ evolution and distribution, given that lateral heat diffusion is likely to be similar in pattern due to the same horizontal mixing scheme applied. As can be seen from Figs. 2 and 3, the OFES2 has a gradually improved agreements with both the EN4 and OFES1. As a matter of fact, we compared these three datasets similarly over 1993-2016 (not shown here), during which the OFES2 is believed to be well spun up. It was found that the spatial distribution of potential temperature change in the OFES2 are much closer to other data compared to the period 1960-2016. However, large discrepancies remain in the temporal evolution of the global and basin OHC even during the recent two decades. The importance of vertical diffusion was justified in Bryan (1987), where the vertical diffusivity was found to play a vital role in the simulations of OGCMs, e.g., the meridional heat transport. In addition, the vertical diffusion of heat itself is directly related to the heat budget according to the primitive equation of temperature. The vertical diffusivity is only available for the OFES2, a limit hampering our further dig into the discrepancies of vertical heat diffusion between the two OFES datasets. In addition, decomposing the vertical heat diffusion into tidal mixing and mixed-layer vertical mixing could also help to isolate the effects of the inclusion of tidal mixing on the ocean state.

On the one hand, in spite of no observational-based constraints, we found that the OFES products, especially the OFES1, did present some of the warming or cooling trend shown by the EN4 and in the literature, demonstrating the adaptability of ocean modelling in simulating the multi-decadal oceanic thermal state. On the other hand, caution is needed when using the results from the OFES2, at least during the first couple of decades; if the vertical mixing was found to be significant in causing the examined differences between the OFES2 and the others, special attention will be called on the vertical mixing scheme validation for the future ocean modelling.

Acknowledgements: This is publication No. 87 of the Sino-Australian Research Consortium for Coastal Management (previously the Sino-Australian Research Centre for Coastal Management). This work was supported by the Key Special Project for Introduced Talents Team of the Southern Marine Science and Engineering Guangdong Laboratory (Guangzhou; GML2019ZD0210). The authors thank Dr. Peter McIntyre for improving the manuscript. The authors acknowledge public access to the data used in this paper from the UK Meteorological Office and the JAMSTEC.

Code and data availability: Both the OFES1 and OFES2 are based on the MOM3, available at https://github.com/momocean/MOM3. The Code used to decompose the potential temperature can be found at http://www.teos-10.org/software.htm. The OFES1 temperature and salinity data are available at 

http://apdrc.soest.hawaii.edu/dods/public ofes/OfES/ncep 0.1 global mmean/salt.info; the OFES2 temperature and salinity data were downloaded from http://www.jamstec.go.jp/esc/fes/dods/OFES2/Monthly/temp.info $\quad$ and http://www.jamstec.go.jp/esc/fes/dods/OFES2/Monthly/salt.info; the EN4 temperature data at https://www.metoffice.gov.uk/hadobs/en4/download-en4-2-1.html.

\section{References}

Abraham, J. P., Reseghetti, F., Baringer, M., Boyer, T., Cheng, L., Church, J., Domingues, C., Fasullo, J. T., Gilson, J., Goni, G., Good, S., Gorman, J. M., Gouretski, V., Ishii, M., Johnson, G. C., Kizu, S., Lyman, J., MacDonald, A., Minkowycz, W.

J., Moffitt, S. E., Palmer, M., Piola, A., Trenberth, K. E., Velicogna, I., Wijffels, S., and Willis, J.: A review of global ocean temperature observations: implications for ocean heat content estimates and climate change, Rev. Geophys., 51, 450-483, doi.org/10.1002/rog.20022, 2013.

AchutaRao, K. M., Ishii, M., Santer, B. D., Gleckler, P. J., Taylor, K. E., Barnett, T. P., Pierce, D. W., Stouffer, R. J., and Wigley, T. M. L.: Simulated and observed variability in ocean temperature and heat content, Proc Natl Acad Sci., 104,1076810773, doi.org/10.1073/pnas.0611375104, 2007.

Allison, L. C., Roberts, C. D., Palmer, M. D., Hermanson, L., Killick, R. E., Rayner, N. A., Smith, D. M., and Andrews, M. B.: Towards quantifying uncertainty in ocean heat content changes using synthetic profiles, Environ. Res. Lett., 14, 084037, doi.org/10.1088/1748-9326/ab2b0b, 2019.

Balmaseda, M. A., Trenberth, K. E., and Källén, E.: Distinctive climate signals in reanalysis of global ocean heat content, Geophys Res Lett., 40, 1754-1759, doi.org/10.1002/grl.50382, 2013.

Bindoff, N. L., and McDougall, T. J.: Diagnosing climate change and ocean ventilation using hydrographic data, J. Phy. Oceanogr., 24, 1137-1152, doi.org/10.1175/1520-0485(1994)024<1137:DCCAOV>2.0.CO;2, 1994.

Carton, J. A., Penny, S. G., and Kalnay, E.: Temperature and salinity variability in the SODA3, ECCO4r3, and ORAS5 ocean reanalyses, 1993-2015, J. Climate., 32, 2277-2293, doi.org/10.1175/JCLI-D-18-0605.1, 2019.

485 Chen, X., Yan, Y., Cheng, X., and Qi, Y.: Performances of seven datasets in presenting the upper ocean heat content in the South China Sea, Adv. Atmos. Sci., 30, 1331-1342, doi.org/10.1007/s00376-013-2132-1, 2013.

Cheng, L., Trenberth, K. E., Palmer, M. D., Zhu, J., and Abraham, J.: Observed and simulated full-depth ocean heat content changes for 1970-2005, Ocean Sci., 12, 925-935, doi.org/10.5194/os-12-925-2016, 2016.

Church, J. A., White, N. J., and Arblaster, J. M.: Significant decadal-scale impact of volcanic eruptions on sea level and ocean 490 heat content, Nature., 438, 74-77, doi.org/10.1038/nature04237, 2005.

Dong, S., Garzoli, S., and Baringer, M.: The role of interocean exchanges on decadal variations of the meridional heat transport in the South Atlantic, J. Phys. Oceanogr., 41, 1498-1511, doi.org/10.1175/2011JPO4549.1, 2011.

Du, Y., Qu, T., Meyers, G., Masumoto, Y., and Sasaki, H.: Seasonal heat budget in the mixed layer of the southeastern tropical Indian Ocean in a high-resolution ocean general circulation model, J. Geophys. Res. Oceans., 110, C04012, doi.org/10.1029/2004JC002845, 2005.

Emery, W.: Water Types and Water Masses, Encyclopedia of Ocean Sciences, doi.org/10.1006/rwos.2001.0108, 4, 3179-3187, 2001.

Gleckler, P. J., Santer, B. D., Domingues, C. M., Pierce, D. W., Barnett, T. P., Church, J. A., Taylor, K. E., Achutarao, K., Boyer, T. P., and Ishii, M.: Human-induced global ocean warming on multidecadal timescales, Nat. Climate Change., 2, 524529, doi.org/10.1038/nclimate1553, 2012. 
Good, S. A., Martin, M., and Rayner, N. A.: EN4: Quality controlled ocean temperature and salinity profiles and monthly objective analyses with uncertainty estimates, J. Geophys. Res. Oceans., 118, 6704-6716, doi.org/10.1002/2013JC009067, 2013.

Häkkinen, S., Rhines, P. B., and Worthen, D.: Warming of the global ocean: Spatial structure and water-mass trends, J. Climate., 29, 4949-4963, doi.org/10.1175/JCLI-D-15-0607.1, 2016.

Jackett, D. R., and McDougall, T. J.: A neutral density variable for the world's oceans, J. Phys. Oceanogr., 27, 237-263, doi.org/10.1175/1520-0485(1997)027<0237:ANDVFT>2.0.CO;2, 1997.

Jayne, S. R., and Laurent, L. C. St.: Parameterizing tidal dissipation over rough topography, Geophys. Res. Lett., 28, 811-814, doi.org/10.1029/2000GL012044, 2001.

510 Kalnay, E., Kanamitsu, M., Kistler, R., Collins, W., Deaven, D., Gandin, L., Iredell, M., Saha, S., White, G., Woollen, J., Zhu, Y., Chelliah, M., Ebisuzaki, W., Higgins, W., Janowiak, J., Mo, K. C., Ropelewski, C., Wang, J., Leetmaa, A., Reynolds, R., Jenne, R., and Joseph, D.: The NCEP/NCAR 40-year reanalysis project, B. Am. Meteorol. Soc., 77, 437-472, doi.org/10.1175/1520-0477(1996)077<0437:TNYRP>2.0.CO;2, 1996.

Large, W. G., McWilliams, J. C., and Doney, S. C.: Oceanic vertical mixing: A review and a model with a nonlocal boundary

515 layer parameterization, Rev. Geophys., 32, 363-403, doi.org/10.1029/94RG01872, 1994.

Lee, S., Park, W., Baringer, M. O. A., Gordon, L., Huber, B. A., and Liu, Y.: Pacific origin of the abrupt increase in Indian Ocean heat content during the warming hiatus, Nature Geosci., 8, 445-449, doi.org/10.1038/ngeo2438, 2015.

Levitus, S., Antonov, J. I., Boyer, T. P., Baranova, O., Garcia, H. E., Locarnini, R. A., Mishonov, A. V., Reagan, J. R., Seidov, D., and Yarosh, E. S.: World ocean heat content and thermosteric sea level change (0-2000 m), Geophys. Res. Lett., 39, 19552010, doi.org/10.1029/2012GL051106, 2012.

Liang, X., Spall, M., and Wunsch, C.: Global ocean vertical velocity from a dynamically consistent ocean state estimate. J. Geophys. Res. Oceans., 122, 8208-8224, doi.org/10.1002/2017JC012985, 2017.

Liang, X., Piecuch, C. G., Ponte, R. M., Forget, G., Wunsch, C., and Heimbach, P.: Change of the global ocean vertical heat transport over 1993-2010, J. Climate., 30, 5319-5327, doi.org/10.1175/JCLI-D-16-0569.1, 2017.

525 Noh, Y., and Kim, H. J.: Simulations of temperature and turbulence structure of the oceanic boundary layer with the improved near-surface process, J. Geophys. Res. Oceans., 104, 15621-15634, doi.org/10.1029/1999JC900068, 1999.

Palmer, M. D., Mcneall, D. J., and Dunstone, N. J.: Importance of the deep ocean for estimating decadal changes in Earth's radiation balance, Geophys. Res. Lett., 38, L13707, doi.org/10.1029/2011GL047835, 2011.

Pierce, D. W., Barnett, T. P., Achutarao, K., Gleckler, P. J., Gregory, J. M., and Washington, W. M.: Anthropogenic warming of the oceans: Observations and model results, J. Clim., 19, 1873-1900, doi.org/10.1175/JCLI3723.1, 2006

Sasaki, H., Sasai, Y., Kawahara, S., Furuichi, M., Araki, F., Ishida, A., Yamanaka, Y., Masumoto, Y., and Sakuma, H.: A series of eddy-resolving ocean simulations in the world ocean-OFES (OGCM for the Earth Simulator) project, Oceans '04 MTS/IEEE Techno-Ocean '04 (IEEE Cat. No. 04CH37600) 3, 1535-1541, 2004.

Sasaki, H., Kida, S., Furue, R., Aiki, H., Komori, N., Masumoto, Y., Miyama, T., Nonaka, M., Sasai, Y., and Taguchi, B.: A global eddying hindcast ocean simulation with OFES2, Geosci. Model Dev., 13, 3319-3336, doi.org/10.5194/gmd-13-33192020, 2020.

Spence, P., Saenko,O. A., Sijp, W., and England, M.: The role of bottom pressure torques on the interior pathways of North Atlantic deep water, J. Phys. Oceanogr., 42, 110-125, doi.org/10.1175/2011JPO4584.1, 2012.

St. Laurent, L. C., Simmons, H. L., and Jayne, S. R.: Estimating tidally driven mixing in the deep ocean, Geophys. Res. Lett., 540 29, 21-21-21-24, doi.org/10.1029/2002GL015633, 2002.

Trenberth, K. E., Fasullo, J. T., Von Schuckmann, K., and Cheng, L.: Insights into Earth's energy imbalance from multiple sources, J. Climate., 29, 7495-7505, doi.org/10.1175/JCLI-D-16-0339.1, 2016. 
https://doi.org/10.5194/gmd-2021-95

Preprint. Discussion started: 20 April 2021

(c) Author(s) 2021. CC BY 4.0 License.

Tsujino, H., Urakawa, S., Nakano, H., Small, R. J., Kim, W. M., Yeager, S. G., Danabasoglu, G., Suzuki, T., Bamber, J. L., Bentsen, M., Böning, C. W., Bozec, A., Chassignet, E. P., Curchitser, E., Boeira Dias, F., Durack, P. J., Griffies, S. M., Harada, 545 Y., Ilicak, M., Josey, S. A., Kobayashi, C., Kobayashi, S., Komuro, Y., Large, W. G., Le Sommer, J., Marsland, S. J., Masina, S., Scheinert, M., Tomita, H., Valdivieso, M., and Yamazaki, D.: JRA-55 based surface dataset for driving ocean-sea-ice models (JRA55-do), Ocean Model., 130, 79-139, doi.org/10.1016/j.ocemod.2018.07.002, 2018.

Von Schuckmann, K., Palmer, M. D., Trenberth, K. E., Cazenave, A., Chambers, D. P., Champollion, N., Hansen, J., Josey, S. A., Loeb, N. G., and Mathieu, P. P.: An imperative to monitor Earth's energy imbalance. Nat. Climate Change., 6, 138-144, 550 doi.org/10.1038/nclimate2876, 2016.

Wang, G., Cheng, L., Abraham, J., and Li, C.: Consensuses and discrepancies of basin-scale ocean heat content changes in different ocean analyses, Clim. Dyn., 50, 2471-2487, doi.org/10.1007/s00382-017-3751-5, 2018.

Wang, X. H., Bhatt, V., and Sun, Y.-J.: Study of seasonal variability and heat budget of the East Australian Current using two eddy-resolving ocean circulation models, Ocean. Dyn., 63, 549-563, doi.org/10.1007/s10236-013-0605-5, 2013.

555 Wunsch, C.: The decadal mean ocean circulation and Sverdrup balance, J. Mar. Res., 69, 417-434, doi.org/ 10.1357/002224011798765303, 2011.

Zanna, L., Khatiwala, S., Gregory, J. M., Ison, J., and Heimbach, P.: Global reconstruction of historical ocean heat storage and transport, Proc. Natl. Acad. Sci., 116, 1126-1131, doi.org/10.1073/pnas.1808838115, 2019. 